\title{
Significant progression of load on the
}

\section{musculoskeletal system with extremely high loads, with rapid weekly weight gains, using the Anatoly Gravitational System, in a I0-week training period}

\author{
This article was published in the following Dove Press journal: \\ Open Access Journal of Sports Medicine \\ 11 October 2013 \\ Number of times this article has been viewed
}

\section{David T Burke' \\ David Tran' \\ Di Cui' \\ Daniel P Burke 2 \\ Samir Al-Adawi ${ }^{3}$ \\ Atsu SS Dorvlo ${ }^{4}$}

'Emory University Medical School, Atlanta, GA, USA; ${ }^{2}$ Georgia College and State University, GA, USA; ${ }^{3}$ Department of Behavioral Medicine, College of Medicine and Health Sciences, Sultan Qaboos University, Muscat, Oman; ${ }^{4}$ Department of Mathematics and Statistics, College of Science, Sultan Qaboos University, Muscat, Oman
Correspondence: David T Burke Department of Rehabilitation Medicine, Emory University Medical School, |44| Clifton Rs NE, Atlanta,

GA 30322, USA

Tel +l 4042908715

Fax +I 4047125895

Email dburke2@emory.edu

\begin{abstract}
In an age of increasing numbers of lifestyle diseases and plasticity of longevity, exercise and weight training have been increasingly recognized as both preventing and mitigating the severity of many illnesses. This study was designed to determine whether significant weight-lifting gains could be realized through the Anatoly Gravitational System. Specifically, this study sought to determine whether this once-weekly weight-training system could result in significant weekly strength gains during a 10 -week training period. A total of 50 participants, ranging in age from 17 to 67 years, completed at least 10 weekly 30 -minute training sessions. The results suggest participants could, on average, double their weight-lifting capacity within 10 sessions. This preliminary study, which would require further scrutiny, suggests the Anatoly Gravitational System provides a rather unique opportunity to load the musculoskeletal system with extremely high loads, with rapid weekly weight gains, using only short weekly training sessions. More studies are warranted to scrutinize these findings.
\end{abstract}

Keywords: Anatoly Gravitational System, weight training, musculoskeletal system

\section{Introduction}

According to the Centers for Disease Control and Prevention, one third of the US population older than 20 years is overweight, and another $35.9 \%$ of US citizens older than 20 years are obese. ${ }^{1}$ To address this issue, interventions targeted both physical activity and nutrition behavior. ${ }^{2,3}$ The idea that exercise keeps us healthy is a commonly held belief. Many see it as a form of medicine, with some advocating that physical activity be considered a vital sign to be taken at each patient's visit to a medical facility. ${ }^{4,5}$ Although some studies have focused on aerobic exercise, a growing number of strength and power training studies have proven that these forms of exercise deliver significant health benefits as well. ${ }^{6}$ Furthermore, some studies suggest that weight training, coupled with aerobic exercise, can help to manage or even prevent certain conditions, including heart disease, diabetes, arthritis, and osteoporosis. ${ }^{7-10}$

When using strength and power training programs, studies have shown that individuals, even those in their 70 s and 80 s, can be expected to see improvements in strength, power, mobility, and agility in as little as 10 weeks. Strength training has also been found to ease pain and improve quality of life. Baker et $\mathrm{a}^{11}$ have also shown that patients with knee osteoarthritis who performed strength training gained strength in their knees, had less pain, functioned better, and reported a better quality of life. Weight training has also been shown to manage or prevent mental conditions. ${ }^{12-15}$ 
When considering methods by which weight training might be undertaken, two common discussions are advanced. These include both those involving the frequency and those involving the intensity of the weight training. The focus of these discussions has often been on advancing loads used in training, with the knowledge that increased loads will result in improved outcomes. These discussions often focus on low repetitions of high intensity or high repetitions of low intensity. Some suggest that to increase strength, highintensity, low-repetition training may be best, whereas to increase endurance, high repetitions of low intensity may be best. ${ }^{16}$ Others have discussed both the optimal and the minimal weight lifted and frequency of training for health benefits, with some noting gains with as little as a single weekly bout of exercise. ${ }^{17,18}$

There is, in fact, evidence suggesting that high-intensity strength training may be more effective at improving some health conditions than low-intensity training. ${ }^{19,20}$ This same training has also been shown to improve strength and speed of walking, ultimately resulting in higher scores on patients' quality-of-life questionnaires. As a treatment for bone mineral density loss, weight training programs have been shown to prevent osteoporosis in some patients. There is evidence that higher-intensity resistance training may result in greater benefits in bone mineral density changes. ${ }^{21}$ The magnitude of training required to produce an effective stimulus for bone remodeling appears to be between a one-repetition maximum and a ten-repetition maximum load. ${ }^{22}$ Research also indicates that virtually all the benefits of resistance training are likely to be obtained in two 15- to 20-minute training sessions a week..$^{23,24}$

The most intense weight resistance program we know of today is a new patented method, the Anatoly Gravitational System. Initially developed in Russia by Anatoly Samodoumov, this system is now protected by patents in the United States and Russia, with training facilities in both countries. Although it has been highlighted in sports magazines, no scientific inquiry has yet explored the system.

This study explores the strength training gains obtained through the use of this weight training program and assesses the loads lifted and loads gained using this very highintensity, low-repetition method. This prospective study was designed to determine whether significant weight-lifting gains could be realized through the Anatoly Gravitational System. We specifically sought to determine whether this once-weekly weight training system could result in significant weekly strength gains during a 10-week training period that would exceed gains achieved by conventional weight-lifting systems.

\section{Methods}

This prospective study included data collected on adult individuals attending the Chubinsky Wellness Center in Atlanta, Georgia, and completing at least 10 weekly exercise sessions. The review of the data collected during training sessions was authorized by the Emory Institutional Review Board. At each exercise session, the participant engaged in four separate exercises. All exercises involved free weights, using a barbell system.

The first of these exercises, belt lift, involves the use of a barbell attached to a hoisting belt that is attached at each end to a connecting star at the end of the weights (Figure 1). When attached, the participant is asked to bend at the waist and place his or her hands on an upper-body support structure. At this point, the participant is forward flexed at the waist to approximately $90^{\circ}$. The hoisting belt is then placed over the lower back and upper pelvic area of the user. For this maneuver, the feet are placed in Russian camp boots, with the feet approximately shoulder-width apart and the knees bent to $45^{\circ}$. With the belt placed over the lower back, the participant is instructed to inhale and to extend the knees from a starting angle of approximately $45^{\circ}$ to near full extension, lifting the weight for approximately 3 seconds. Loads are added until the instructor determines the form of the lift is faltering, indicating that maximal weightlifting capacity is being approached. After this lift, the weight is reduced by $45 \mathrm{~kg}$ and the participant is asked to complete three additional repetitions as a cool-down maneuver. The total number of lifts at this station averages 10 .

With participants wearing a weightlifting belt, the second lift, hand lift, is performed using a barbell system positioned within a metal track such that the starting point of a lift can occur with the patient's arms fully extended and the knees bent at $45^{\circ}$ (Figure 2). The participants' hands are placed in gloves, with the wrist attached to the barbell by straps,

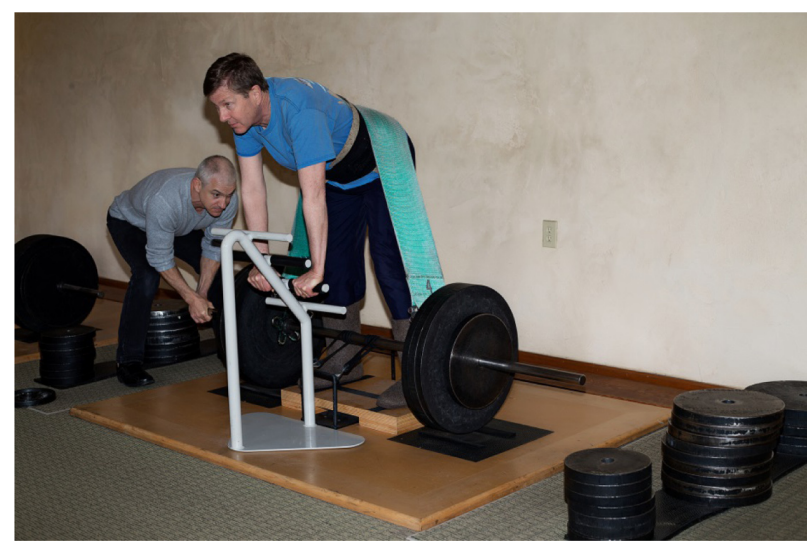

Figure I Belt lift: barbell system positioned according to the Anatoly Gravitational System. 
so as to assist with the grip of the loads. The participant is asked to keep the back aligned in an upward position, to lean away from the bar at $15^{\circ}$, and to retract the scapula. From this position, the knees are extended, lifting the loads for a period of less than 3 seconds. According to the subject's capability, the loads are sequentially increased until the instructor again notes a faltering of form, indicating maximal weight-lifting capacity is being approached. With this weight achieved, the weight is reduced by $45 \mathrm{~kg}$ and the participant is asked to repeat the extension maneuver for three additional repetitions.

The third lift, chest lift, is performed from a lying position, using weight-lifting gloves. The loads are again positioned within a track system such that only up-and-down movements are permitted. The participant's position is such that the barbell is directly above the chin. The grip is slightly wider than shoulder width in the beginning position. A chest press maneuver is then completed to full extension (Figure 3). As with the other exercises, weight is added until the subject demonstrates a faltering in form, indicating maximal weightlifting capacity is being approached. When this weight is achieved, the weight is reduced by $45 \mathrm{~kg}$ and the participant is asked to complete three additional repetitions.

The fourth lift, leg lift, is performed from a lying position, using a barbell system contained within tracks. Wearing tennis shoes, the participant lies on the mat with the soles of the shoes placed at the midposition of the plantar fascia. The starting position is determined such that the knees are bent at a $45^{\circ}$ angle, with the participant instructed to extend the knees, lifting the loads for a period of less than 3 seconds (Figure 4). Loads are then added as in the previous exercises until the instructor determines the form of the subject is faltering, indicating maximal weight-lifting capacity is being approached. The weight is then reduced by $45 \mathrm{~kg}$ and the participant

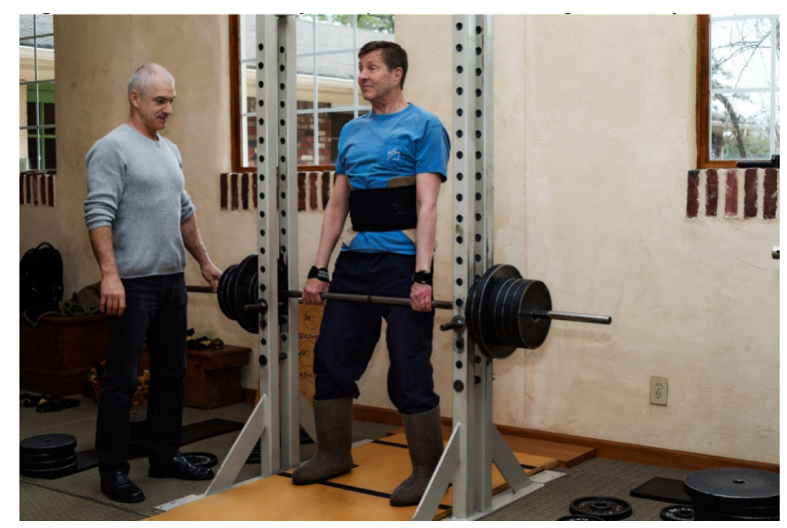

Figure 2 Hand lift: barbell system positioned according to Anatoly Gravitational System.

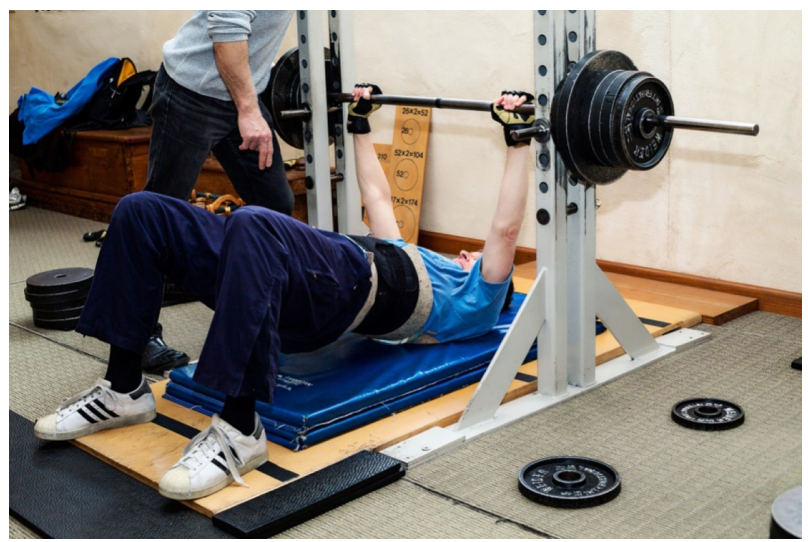

Figure 3 Chest lift: barbell system positioned according to Anatoly Gravitational System.

completes three additional repetitions. At this weight, the subject's foot is moved anteriorly and posteriorly on the bar such that the weight is lifted from contact positions just anteriorly to the calcaneus and two additional positions until a final lift at the metatarsophalangeal joint. The final maneuver, using the previously described positioning, occurs using the final weight. The instructor asks the participant to lift the loads while the barbell is slowly rotated by the instructor, moving the contact position of the foot from the metatarsophalangeal joint to the anterior calcaneus and back.

With all these exercises completed, the participant is instructed to refrain from eating for a period of 2 to 3 hours after completion of the training. The weekly exercises are completed in the same manner, with the end weight determined by the ability of the participant to maintain form during the performance of each.

Data were recorded at each weight-lifting session, including maximum weight lifted at each of the four weight stations described earlier. The sessions continued for at least 10 weeks.

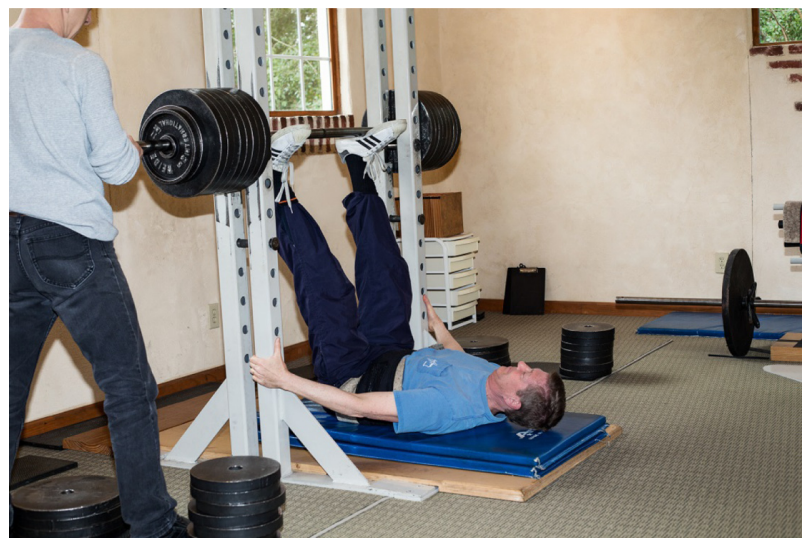

Figure 4 Leg lift: barbell system positioned according to Anatoly Gravitational System. 
Table I Summary of loads lifted using the Anatoly Gravitational System during a I0-week training period

\begin{tabular}{|c|c|c|c|c|c|c|c|c|c|c|c|c|}
\hline & \multicolumn{4}{|c|}{ Mean loads lifted, kg } & \multicolumn{4}{|c|}{ Minimum loads lifted, kg } & \multicolumn{4}{|c|}{ Maximum loads lifted, kg } \\
\hline & Belt & Chest & Hand & Leg & Belt & Chest & Hand & Leg & Belt & Chest & Hand & Leg \\
\hline Session I & 271 & 110 & 115 & 256 & $14 \mid$ & 50 & 55 & 141 & 447 & 259 & 224 & 376 \\
\hline Session 2 & 323 & 124 & 135 & 292 & 164 & 60 & 55 & 164 & 518 & 282 & 268 & 455 \\
\hline Session 3 & 369 & 136 & $|5|$ & 323 & 188 & 66 & 69 & 211 & 565 & 329 & 271 & 534 \\
\hline Session 4 & 408 & 145 & 166 & 347 & 211 & 69 & 79 & 235 & 636 & 376 & 295 & 518 \\
\hline Session 5 & 442 & 152 & 177 & 367 & 235 & 69 & 79 & 245 & 660 & 400 & 318 & 499 \\
\hline Session 6 & 472 & 156 & 184 & 382 & 259 & 256 & 79 & 259 & 707 & 424 & 295 & 494 \\
\hline Session 7 & 498 & 160 & 189 & 395 & 282 & 69 & 79 & 269 & 730 & 447 & 295 & 542 \\
\hline Session 8 & 519 & 162 & 196 & 407 & 306 & 69 & 84 & 282 & 754 & $47 I$ & 318 & 542 \\
\hline Session 9 & 539 & 166 & 200 & 414 & 329 & 74 & 93 & 292 & 786 & 494 & 318 & 542 \\
\hline Session 10 & 556 & 167 & 204 & 422 & 329 & 79 & 93 & 292 & 786 & 518 & 328 & 542 \\
\hline
\end{tabular}

There were no interruptions in the training sessions of these participants as a result of injuries occurring during the training sessions. Only the loads lifted in the first 10 weeks are reported here.

\section{Statistical analysis}

We assessed changes in the lifting capacities using repeated measures analysis of variance tests. We used Bonferroni multiple comparisons to show differences. The anticipated weight-lifting parameters for males versus females were calculated as reported elsewhere. ${ }^{25}$ Graphs are drawn to illustrate the changes. Results are discussed at the $5 \%$ significance level. We performed the analysis using SPSS version 20.0 (IBM Corporation, Armonk, NY, USA).

\section{Results}

For this study, 50 subjects who participated in the Anatoly Gravitational System were analyzed. The majority of the participants have had some resistance training experience. Participant's ages ranged from 17 to 67 years, with an average age of 49 years. Approximately $60 \%$ of the participants were between 35 and 55 years of age.

\section{Belt-lifting system}

The loads lifted by these individuals at the first session ranged from 141 to $447 \mathrm{~kg}$, with an average initial weight lift of $297 \mathrm{~kg}$ (standard deviation, $66 \mathrm{~kg}$; Table 1). In the tenth session, the loads lifted ranged from a low of $329 \mathrm{~kg}$ to a high of $786 \mathrm{~kg}$, with an average lift of $556 \mathrm{~kg}$ (Figure 5).

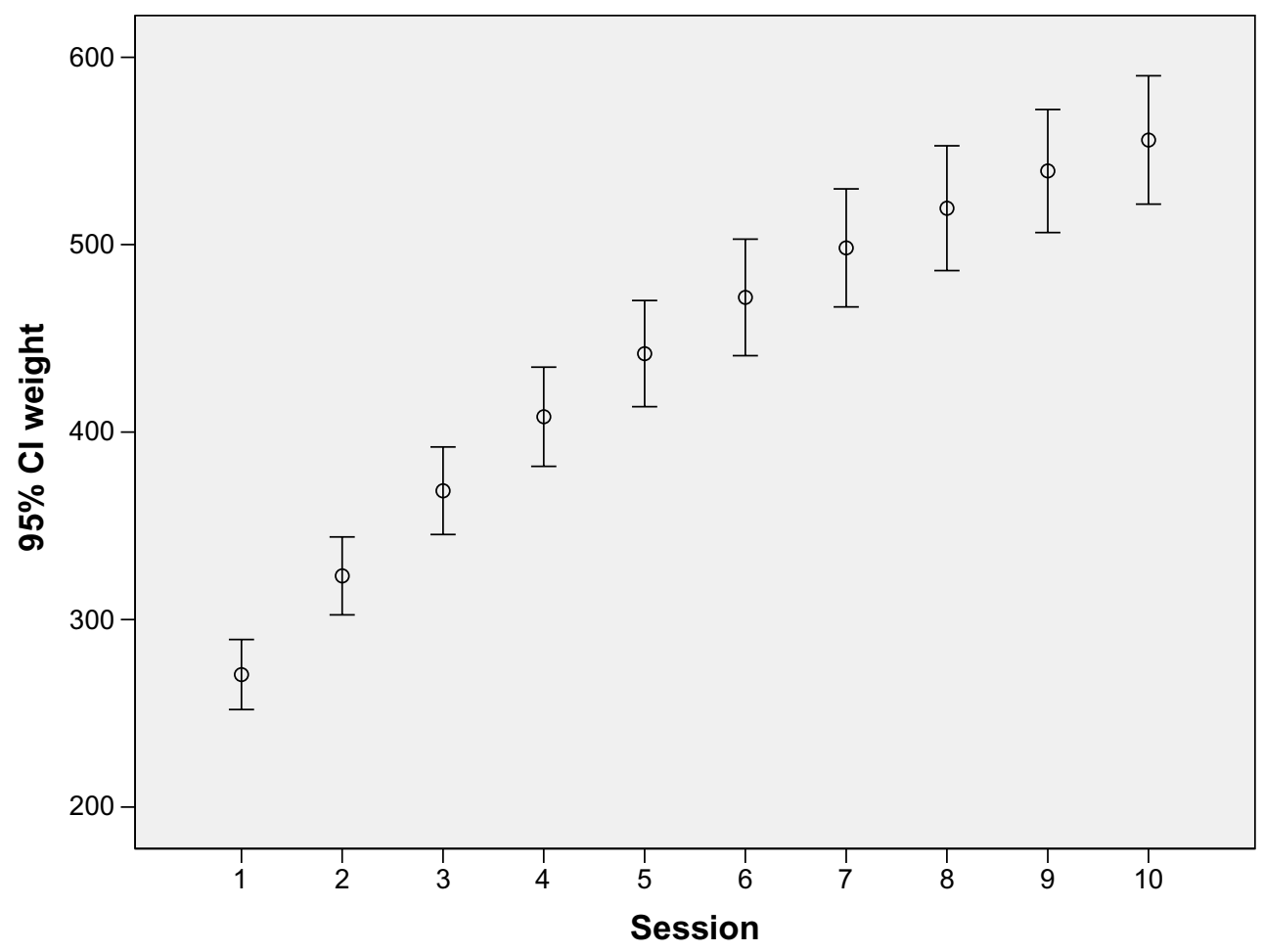

Figure 5 Average weight lifted: belt lift. Abbreviation: $\mathrm{Cl}$, confidence interval. 


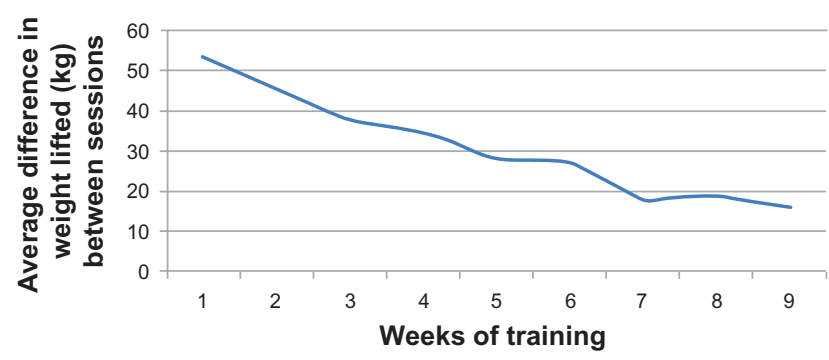

Figure 6 Average gain per week with belt lift.

These data demonstrate that the average kilograms lifted increased rapidly during the first sessions. However, the average gain between sessions decreased from $53 \mathrm{~kg}$ between sessions 1 and 2 to $16 \mathrm{~kg}$ between sessions 9 and 10 (Figure 6). A repeated measures analysis shows that weekly changes increased regularly, and Bonferroni multiple comparisons suggest all weekly changes are significant.

\section{Hand lift}

For the hand lift exercise, the average starting weight lifted was $115.45 \mathrm{~kg}$ (Figure 7), with initial loads ranging from 55.45 to $224.55 \mathrm{~kg}$. In the tenth session, the loads lifted by the same individuals ranged from 97.73 to $271.82 \mathrm{~kg}$, with an average weight lifted being $204.45 \mathrm{~kg}$. As with the belt lift system, the greatest weekly gains occurred in the early sessions, with $19.64 \mathrm{~kg}$ gained between session 1 and session 2 and only $3.64 \mathrm{~kg}$ gained between session 9 and session 10 (Figure 8). The average weight gain per session during the 10 weeks was $9.68 \mathrm{~kg}$. A repeated measures analysis showed that weekly changes increased regularly. Bonferroni multiple comparisons suggest all weekly changes were significant except for weeks 6-7, 8-9, and 9-10.

\section{Chest press}

For the chest press, the initial loads lifted ranged from 50.45 to $259.09 \mathrm{~kg}$, with an average weight lifted of $110.45 \mathrm{~kg}$ (Figure 9). In the tenth session, loads lifted ranged from 79.09 to $519.09 \mathrm{~kg}$, with an average weight lifted of $167.27 \mathrm{~kg}$. As with the other two exercises, the greatest gains between sessions occurred early, with $14.23 \mathrm{~kg}$ gained between sessions 1 and 2 and $1.45 \mathrm{~kg}$ gained between sessions 9 and 10 (Figure 10). A repeated measures analysis showed that weekly changes increased regularly. Bonferroni multiple comparisons suggest the first 6 weeks' changes were significant. From week 7 only, week 8-9 change was not significant.

\section{Leg press}

For the leg press, initial loads lifted ranged from 140.91 to $377.27 \mathrm{~kg}$. The average weight lifted on this first session was $256.64 \mathrm{~kg}$. In the tenth session, loads lifted ranged

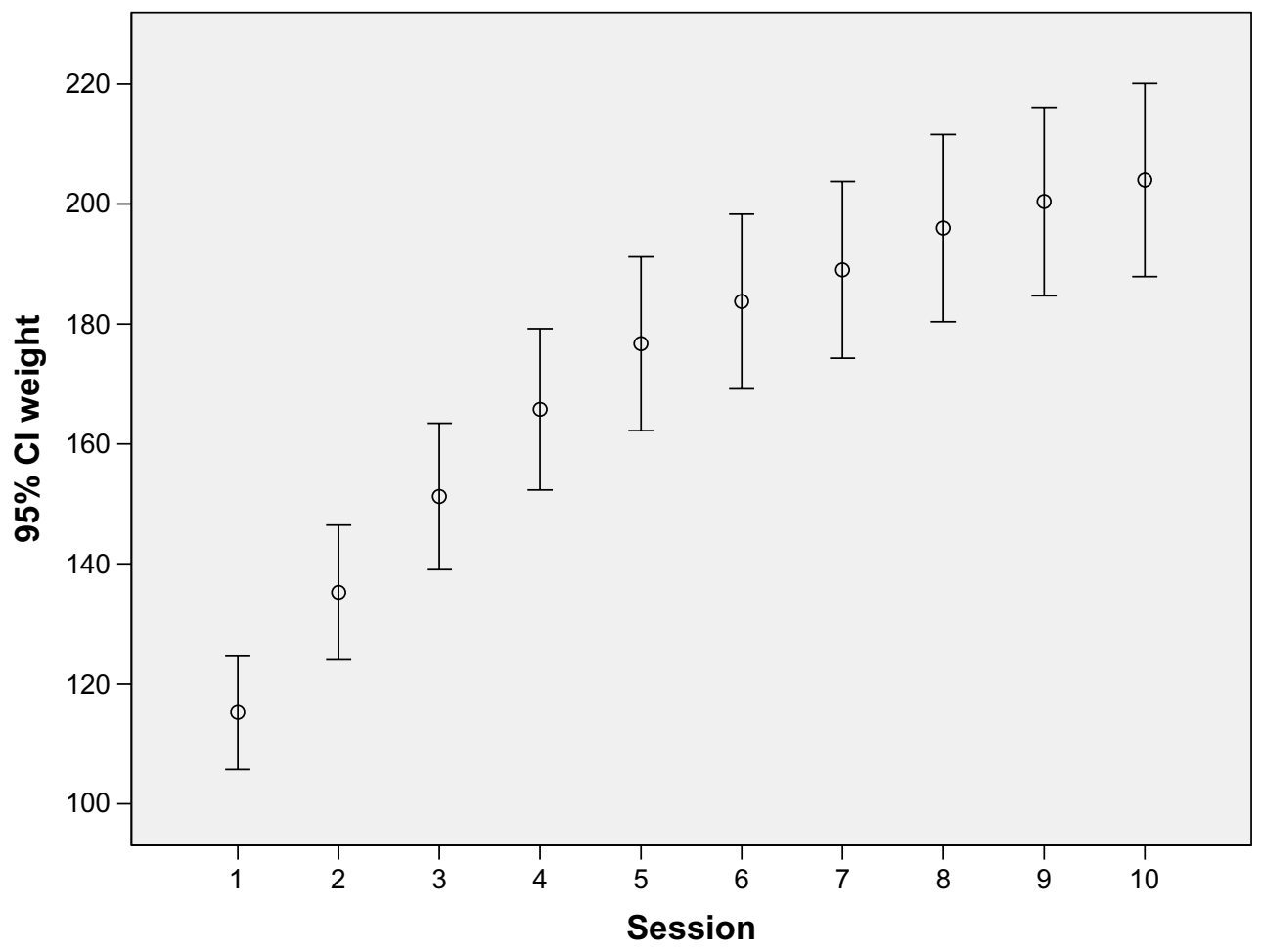

Figure 7 Average weight lifted: hand lift. 


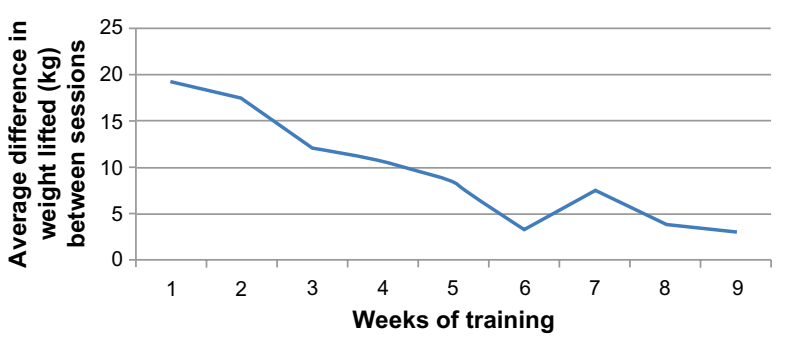

Figure 8 Average gain per weeks with hand lift.

from 292.73 to $542.73 \mathrm{~kg}$, with an average of $423.05 \mathrm{~kg}$ (Figure 11). The average gain per session was $18.5 \mathrm{~kg}$. As with the other exercises, the greatest gains occurred in the first sessions, with fewer gains realized in the later sessions. The average weight gain between sessions 1 and 2 was $35.64 \mathrm{~kg}$ gained, with only $8.32 \mathrm{~kg}$ gained between sessions 9 and 10 (Figure 12). A repeated measures analysis showed that weekly changes increased regularly. Bonferroni multiple comparisons suggest all weekly changes except those in week 8-9 were significant.

\section{Discussion}

This study is the first to demonstrate the effectiveness of a novel weight-lifting system, the Anatoly Gravitational System. In this 50-subject prospective study, we found that participants could lift maximum load at each training session, with weekly changes increased regularly and significantly. This was achieved with a relatively smaller time investment compared with traditional exercise regimes. It is possible that the initial noted gain could be partly attributed to previous experience, as most of the participants had some exposure to resistance training. However, the fact remains that there were regular and, in almost all cases, significant weekly increases. Therefore, the effect of learning appears to have played a minor role on the presently observed trend. These findings give validation to the claims of the program's proponents that participants could achieve the lifting of extremely heavy loads and a significant progression of these loads with training sessions only once a week.

Traditionally, it has been suggested that strength training be engaged using $60 \%$ of a single repetition of maximum weight 3 days per week in untrained individuals and $80 \%$ of a single repetition of maximum weight for 2 days a week in trained individuals to achieve maximal gain. ${ }^{26}$ More researchers, however, are exploring the potential benefits of higher-intensity resistance training. In a study of untrained men older than 60 years, $85 \%-90 \%$ of a single repetition of maximum weight was found to exhibit positive intramuscular, cardiovascular, and metabolic changes. ${ }^{27} \mathrm{In}$ addition, the same study found that high-intensity exercise was well-tolerated by the elderly population and that the benefit achieved is similar to that seen in younger subjects. In further studies comparing high-intensity versus low-intensity progressive resistance exercises, it was found that greater benefits were achieved using high-intensity progressive resistance exercises. ${ }^{28,29}$ The Anatoly Gravitational System is a unique strength-training regimen that was first patented in the United States. ${ }^{30}$ It uses progressive, high-intensity leg

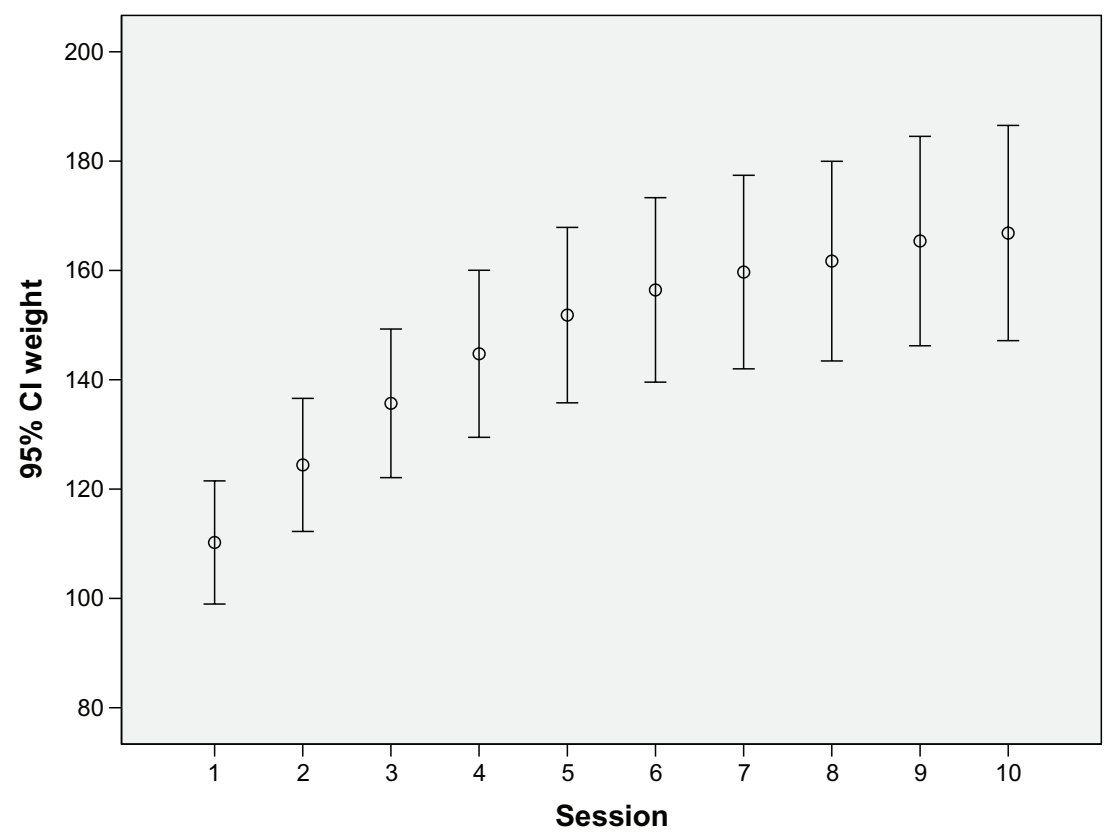

Figure 9 Average weight lifted: chest press. Abbreviation: $\mathrm{Cl}$, confidence interval. 


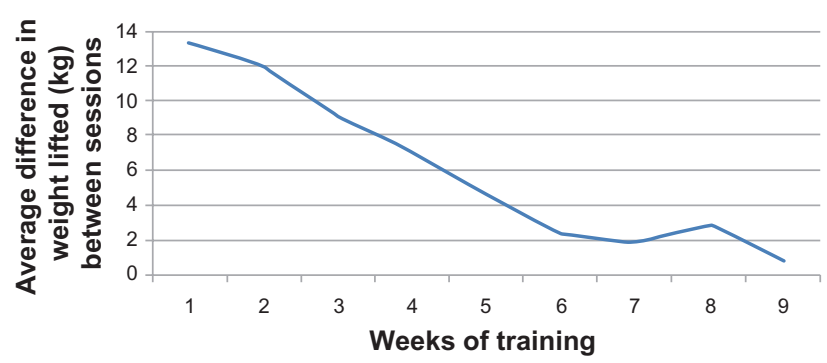

Figure 10 Average gain per week with chest press.

extension as the critical initial exercise that allows weight bearing to be entirely located in the legs and pelvis.

In this study, we analyzed the training records of 50 consecutive participants who completed at least 10 weekly, 30-minute training sessions. We found that despite high average starting loads, participants could on average double their weight-lifting capacity within 10 sessions, with those loads lifted exceeding loads reported in other weightlifting regimens.

There are several limitations to this study. First, this study involved only those individuals who completed at least 10 sessions. Thus the study did not review the gains made by those who participated in fewer sessions or the reasons for the interruption of their training. In addition, there was no direct comparison made between subjects using this exercise system and a matched group participating in other more traditional systems. Inclusion of control group in the future study is therefore imperative. However, in a comparison using historical data, the Anatoly Gravitational System seems to suggest participants are able to load their musculoskeletal system with loads at a more accelerated rate than previously considered. As no injuries were reported to the gym staff during the study, the risk-to-reward benefit ratio seems low. Given these loads, the relative risk of injury using the system certainly warrants further study. In addition, this study evaluated only strength gained during the 10 -week study duration. Although strength is a good marker for general neuromuscular health, and although previous studies are suggestive that improved strength is associated with improved health, specific health parameters and gains of the participants reviewed in this article were not studied.

Second, although in principle this study highlights new discourse in exercise and training with implications for health and performance, it requires a more rigorous experimental methodology and control of the volume of training and the use of a control group using conventional training methodology. It is worthwhile to note that significant strength gains can be achieved with almost any protocol and in people with a wide age range. Therefore, it is not surprising, and may even

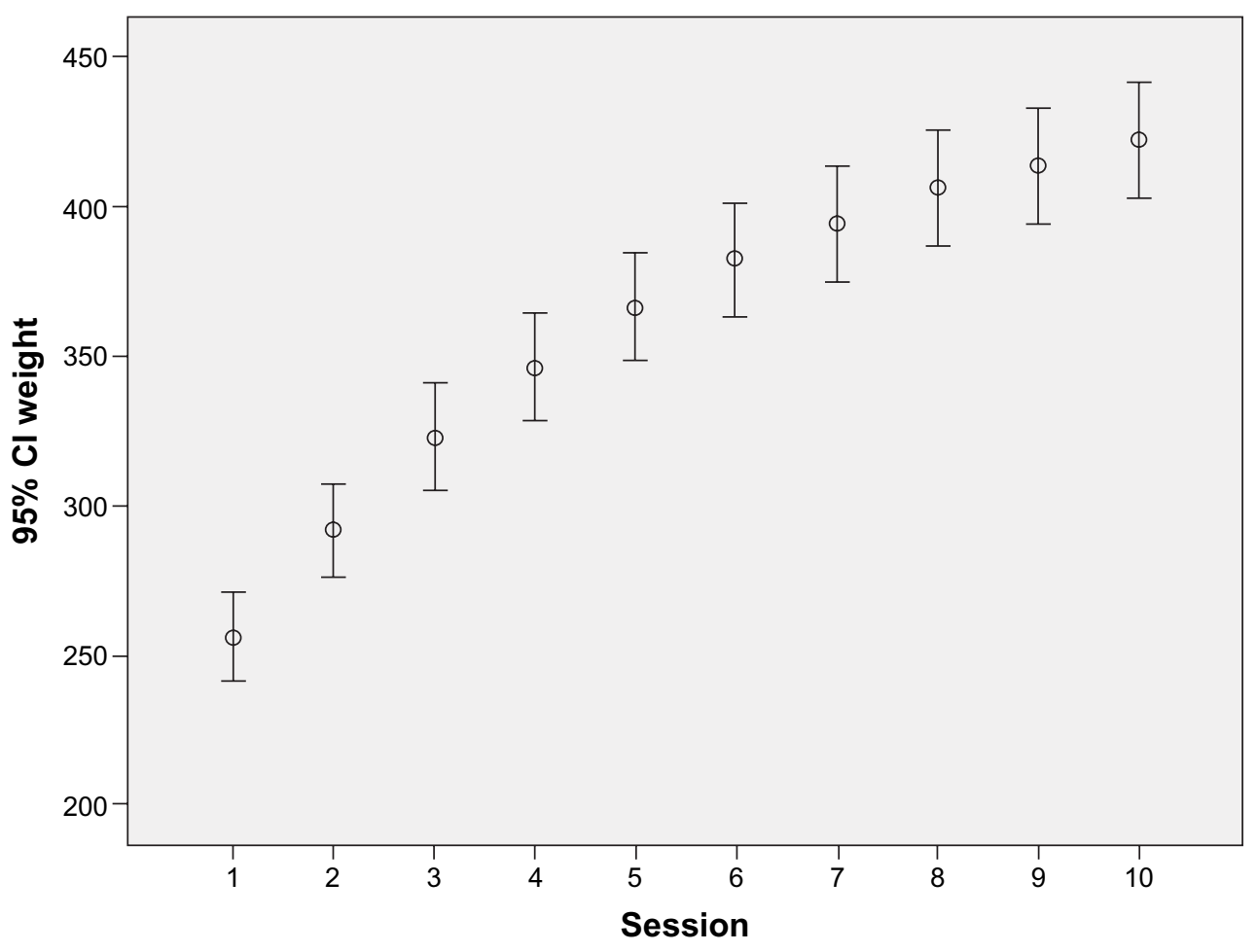

Figure I I Average weight lifted: leg press. Abbreviation: $\mathrm{Cl}$, confidence interval. 


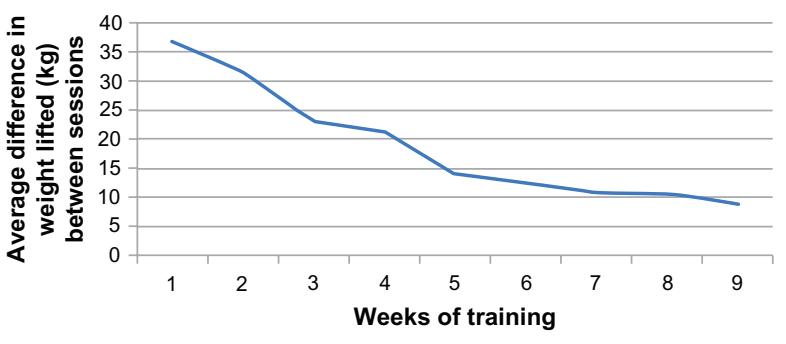

Figure 12 Average gain per week using leg press.

be expected, that the Anatoly Gravitational System will also result in significant strength gains during a 10 -week training period. What the current study does not address is whether this system is better, more efficient, less costly, or safer than other strength training programs. This study did not have a comparison group. Obviously this is one of the major flaws of the current study. If efficacy of a new training strategy is to be considered, then a comparison group must be present for the data. Addressing such a methodological deficit in future studies is therefore imperative.

In conclusion, this study found that the Anatoly Gravitational System provides a rather unique opportunity to load the musculoskeletal system with extremely high loads, with rapid weekly weight gains using only short weekly training sessions. Further study to review the health benefits and the risk of injury of this weight-lifting system is certainly warranted.

\section{Acknowledgment}

We thank all the individuals who volunteered to participate in this study.

\section{Disclosure}

The authors report no conflicts of interest in this work.

\section{References}

1. Centers for Disease Control and Prevention. Obesity and Overweight. Atlanta, GA: Centers for Disease Control and Prevention. Available from: http://www.cdc.gov/nchs/fastats/overwt.htm. Accessed June 2, 2013.

2. Sharma M. Behavioural interventions for preventing and treating obesity in adults. Obes Rev. 2007;8(5):441-449.

3. Warburton DE, Nicol CW, Bredin SS. Health benefits of physical activity: the evidence. CMAJ. 2006;174(6):801-809.

4. Sallis RE. Exercise is medicine and physicians need to prescribe it! $\mathrm{Br}$ J Sports Med. 2009;43(1):3-4.

5. Hellénius ML, Sundberg CJ. Physical activity as medicine: time to translate evidence into clinical practice. Br J Sports Med. 2011;45(3):158.

6. Pollock ML, Franklin BA, Balady GJ, et al. AHA Science Advisory. Resistance exercise in individuals with and without cardiovascular disease: benefits, rationale, safety, and prescription: An advisory from the Committee on Exercise, Rehabilitation, and Prevention, Council on Clinical Cardiology, American Heart Association; Position paper endorsed by the American College of Sports Medicine. Circulation. 2000;101(7):828-833.
7. Iwamoto J, Sato Y, Takeda T, Matsumoto H. Effectiveness of exercise in the treatment of lumbar spinal stenosis, knee osteoarthritis, and osteoporosis. Aging Clin Exp Res. 2010;22(2):116-122.

8. Lucini D, de Giacomi G, Tosi F, Malacarne M, Respizzi S, Pagani M. Altered cardiovascular autonomic regulation in overweight children engaged in regular physical activity. Heart. 2013;99(6):376-381.

9. Yardley JE, Kenny GP, Perkins BA, et al. Resistance versus aerobic exercise: acute effects on glycemia in type 1 diabetes. Diabetes Care. 2013;36(3):537-542.

10. Burke DT, Al-Adawi S, Lee YT, Audette J. Martial arts as sport and therapy. J Sports Med Phys Fitness. 2007;47(1):96-102.

11. Baker KR, Nelson ME, Felson DT, Layne JE, Sarno R, Roubenoff R. The efficacy of home based progressive strength training in older adults with knee osteoarthritis: a randomized controlled trial. J Rheumatol. 2001;28(7):1655-1665.

12. Herring MP, O'Connor PJ, Dishman RK. The effect of exercise training on anxiety symptoms among patients: a systematic review. Arch Intern Med. 2010;170(4):321-331.

13. Cassilhas RC, Viana VA, Grassmann V, et al. The impact of resistance exercise on the cognitive function of the elderly. Med Sci Sports Exerc. 2007;39(8):1401-1407.

14. Tsutsumi T, Don BM, Zaichkowsky LD, Takenaka K, Oka K, Ohno T. Comparison of high and moderate intensity of strength training on mood and anxiety in older adults. Percept Mot Skills. 1998;87(3 Pt 1): 1003-1011.

15. O'Connor PJ, Herring MP, Caravalho A. Mental health benefits of strength training in adults. Am J Lifestyle Med. 2010;4(5):377-396.

16. American College of Sports Medicine. American College of Sports Medicine position stand. Progression models in resistance training for healthy adults. Med Sci Sports Exerc. 2009;41(3):687-708.

17. Lee IM, Hsieh CC, Paffenbarger RS Jr. Exercise intensity and longevity in men. The Harvard Alumni Health Study. JAMA. 1995;273(15): $1179-1184$

18. Wisløff U, Nilsen TI, Drøyvold WB, Mørkved S, Slørdahl SA, Vatten LJ. A single weekly bout of exercise may reduce cardiovascular mortality: how little pain for cardiac gain? 'The HUNT study, Norway'. Eur J Cardiovasc Prev Rehabil. 2006;13(5):798-804.

19. Baechle TR, Earle RW, editors. Essentials of Strength Training and Conditioning. Champaign, IL: Human Kinetics; 2008.

20. Singh NA, Stavrinos TM, Scarbek Y, Galambos G, Liber C, Fiatarone Singh MA. A randomized controlled trial of high versus low intensity weight training versus general practitioner care for clinical depression in older adults. J Gerontol A Biol Sci Med Sci. 2005;60(6): 768-776.

21. Maddalozzo GF, Snow CM. High intensity resistance training: effects on bone in older men and women. Calcif Tissue Int. 2000;66(6): 399-404.

22. Kraemer WJ. General adaptations to resistance and endurance training programs. In: Baechle T, editor. Essentials of Strength Training and Conditioning. Champaign, IL: Human Kinetics; 1994:127-150.

23. Winett RA, Carpinelli RN. Potential health-related benefits of resistance training. Prev Med. 2001;33(5):503-513.

24. Carpinelli RN, Otto RM. Strength training. Single versus multiple sets. Sports Med. 1998;26(2):73-84.

25. Rippetoe M, Kilgore L. Practical Programming for Strength Training. 2nd ed. Wichita, TX; 2009.

26. Rhea MR, Alvar BA, Burkett LN, Ball SD. A meta-analysis to determine the dose response for strength development. Med Sci Sports Exerc. 2003;35(3):456-464.

27. Hagerman FC, Walsh SJ, Staron RS, et al. Effects of high-intensity resistance training on untrained older men. I. Strength, cardiovascular, and metabolic responses. J Gerontol A Biol Sci Med Sci. 2000;55(7): B336-B346.

28. Peterson MD, Rhea MR, Sen A, Gordon PM. Resistance exercise for muscular strength in older adults: a meta-analysis. Ageing Res Rev. 2010;9(3):226-237. 
29. Seynnes O, Fiatarone Singh MA, et al. Physiological and functional responses to low-moderate versus high-intensity progressive resistance training in frail elders. J Gerontol A Biol Sci Med Sci. 2004;59(5): 503-509.
30. Anatoly Ivanovich Samodoumov, inventor; Anatoly Ivanovich Samodoumov, assignee. System, method and apparatus for performing weight training exercises. United States patent US 6544150 B1. April 8, 2003.

Open Access Journal of Sports Medicine

\section{Publish your work in this journal}

Open Access Journal of Sports Medicine is an international, peer-reviewed, open access journal publishing original research, reports, reviews and commentaries on all areas of sports medicine. The manuscript management system is completely online and includes a very quick and fair peer-review system.
Visit http://www.dovepress.com/testimonials.php to read real quotes from published authors. 